\title{
Expected Competencies from University Graduates for Employment in Serbia
}

DOI: 10.7595/management.fon.2021.0006

Abstract:

Research Question: This paper investigates into which competencies and competency areas are essential for graduates to be employable in Serbia. Motivation: The research was conducted with the aim to recommend to the Faculty of Organizational Sciences to adjust their curriculum, so that graduates could acquire competencies necessary for employment at junior positions. Combining qualitative and quantitative approaches, the paper includes required competencies according to popular reports, analysis of vacancies for junior positions in the field of Management and IT, focus groups and surveys conducted in companies in Serbia. Idea: The main idea of the research was to empirically evaluate the need and importance of general competencies for performing a job at junior positions. Participants in the research were experts from human resource management departments and domain experts from different fields who participate in the selection process. Data: During the research, 52 competencies from world reports, 60 competencies from open job vacancies, and 69 competencies during the focus group were analyzed. The questionnaire was created based on 29 competencies that were results from the qualitative research and filled out by 118 representatives from companies from different business domains. Tools: Content analysis of reports and vacancy ads, focus group report and statistical analysis of survey data ( $t$ test, Principal component analysis) were used to draw conclusions about required competencies for junior positions in the Serbian market and to categorize them. Findings: Competencies that are expected from future employees are to be socially skilled leaders capable of solving problems and intrinsically motivated to create and to be productive. Above all, they should be able to learn continuously. Specifically, when comparing managerial junior positions to junior IT professionals, it seems more important to be competitive, have strong presentation skills and to be conscientious. Contribution: Competencies important for graduates' employability in Serbia are identified and grouped in different competency areas based on what universities' curricula could be adapted.

Keywords: competencies, competency categorisation, graduates, labour market, employability

JEL Classification: J24, I23, M53

\section{Introduction}

The concept of competencies is heterogeneous and includes knowledge, abilities, skills, experiences, and behaviours, which are important for an individual to be able to perform at an expected level (El Asame \& Wakrim, 2018; Maaleki, 2018). Employers face difficulties recruiting employees for junior positions due to the graduates' lack of professional competencies (Gawrycka, Kujawska, \& Tomczak, 2020: Varga et al., 2016). The demand for skills, knowledge, and abilities are constantly changing, so the challenging expectation of universities and educators is to prepare students for careers in the future (Pompa, 2015) by adapting curriculum to these demands (Ritter et al., 2017). This is where Competency-based education (CBE) becomes important since it focuses on understanding the competencies that students need in order to perform their job successfully, practical application of knowledge and skills (Johnstone \& Soares, 2014) and the roles that young people will play in the society (Gervais, 2016). In order to suggest what competencies should be developed through the faculty curriculum, this paper will provide insight into the employers ' expectations of tertiary education graduates in Serbia for entering the labour market. 
In the second section of the article, we identify the problem in the context of previous research while providing the theoretical background for the research. This is followed by a description of the methodology used and results gained from both qualitative and quantitative analysis. In the final section, we will problematize our results in the broader context providing ideas for further research and curricula guidelines.

\section{Theoretical Considerations and Identifying the Problem}

Technological evolution has brought substantial change in the domain of work, workplace and workforce. It is found that technological competencies will increase by 69 percent in the United States and 65 percent in Europe by 2030 (Bughin et al., 2018). Researchers agree that we are witnessing the skills shift. While some jobs will disappear and some others emerge, the key skill imposed on organizations and employees would be their adaptability and flexibility, especially in the domain of upgrading and acquiring knowledge and learning new skills (Bedwell, Fiore \& Salas, 2014).

Researchers identified different skills and personal attributes required from graduates to make them employable. They mentioned analytical, technical, communication, entrepreneurial, decision-making and problem-solving, interpersonal and teamwork skills. Among personal attributes, self-motivation, selfawareness, independence, self-confidence, emotional intelligence, flexibility and adaptability are mentioned (Esser et al., 2018; Hodge \& Lear, 2011). It seems that students and graduates have to invest more in obtaining skills and developing less trainable self attributes than in the knowledge of particular subjects.

Finch (2016) differentiates among intellectual, personal resources, as well as Meta and Job specific skills and integrated dynamic capabilities, developed from the employability perspective. Roughly, these competencies might be classified as those concerning "hard" and "soft" skills (Pang, 2018). Nevertheless, it seems that the most usual framework considers a model similar to Khan's (2018) with delivery related, interpersonal and strategic competencies developing into employable skills. Underlining the multidimensionality of the concept, some scholars have tendencies to organize competencies hierarchically, with levels such as behavioural, conscious and unconscious, given by Volery (2013), cognitive, functional, social and meta by Bharwani and Talib (2017), and affective and cognitive by Chen (2020). While some authors offer and compare different approaches to analyses and assess a variety of competencies (Silva, 2020), others propose frameworks for structuring the domain (area) of employees' competencies. Agnihotri (2018) gave a profound overview of competency classifications delineating generic and specific skills.

While digital competencies are crucial in the contemporary context, the competencies that go along with predictability, memory capacity and other technological advances are those that are pitfalls. Employers are expecting developed soft skills (Hurrell, 2016), solid interpersonal skills (Kleckner \& Marshall, 2014), skills that machines cannot learn (Bughin et al., 2018). That creates a growing demand for entrepreneurship skills such as creativity, innovativeness, initiative (Bughin et al., 2018), resilience, ability to cope with difficult situations and new environments (Perez-Lopez, Gonzalez-Lopez, \& Rodríguez-Ariza, 2016), while the most weight is put on cognitive skills such as complex information processing, decision making, creative problem solving and critical thinking (Weaver \& Kulesza, 2014). Silveyra and colleagues (2020), focusing on educational goals, discriminate the categories of entrepreneurship, management and business, human resources (including leadership dimensions) and interpersonal competencies. Sangka et al. (2019) define individual, job demands and organizational environment competencies of managers, while emphasizing analytical and goal setting skills, as well as ethical and cultural awareness. These competencies are especially relevant for business and Information technologies (IT) students, preparing them to respond to the labour market demands (Khoo, Zegwaard, Adam, 2018; Suarta et al., 2017; Ritter et al., 2017).

Bughin et al. (2018) give some predictions for 2030, with the demand for basic cognitive, physical and manual skills decreasing, and leadership and human resource skills becoming more important. Predictions also say that the demand for social and emotional skills in the market will increase by $26 \%$ in America, regardless of the industry, while the demand for cognitive skills (creativity, critical thinking, decision-making and processing of complex information) will increase by $19 \%$. It is obvious that digital literacy, critical thinking, problem solving, initiative, creativity and innovation, teamwork and lifelong learning capacity will become vital as the so-called workplace readiness skills (Crespin et al., 2017). Focusing on the idea that employability of youth labour force is based on their current (up to date) competencies, education and increasing the competencies of students will become the key factors. Crespin et al. (2017) have found that candidates for junior positions have problems with critical thinking and problem-solving skills, positive work ethics, initiative and self-direction, time, task, and resource management. The solution for bridging the competency gaps could be in adjusting the universities' curricula based on market needs. 


\section{An Empirical Research of Required Competencies: Research Methodology}

Research into the demand for competencies of graduates was conducted by a team from the Faculty of Organizational Sciences, University of Belgrade (FOS), with the aim of identifying general competencies essential for employment in junior positions so that Faculty should adjust its curricula.

The FOS is recognized as the leading educational institution in Serbia with accredited study programmes in the field of Information technologies and Management, at the level of Bachelor, Master and PhD studies, with more than 4000 active students at the moment. The Faculty has two undergraduate study programmes: IT and Management. In the Faculty curricula, the first two years are general education and consist of general subjects. From the third year of the studies, students are offered more specialized courses for each specific field. Students who graduate from the FOS, in addition to acquiring contemporary knowledge in the specific field of study, are also able to work in teams, have good communication skills and are able to quickly adopt change.

The research was conducted in two phases (Figure 1).

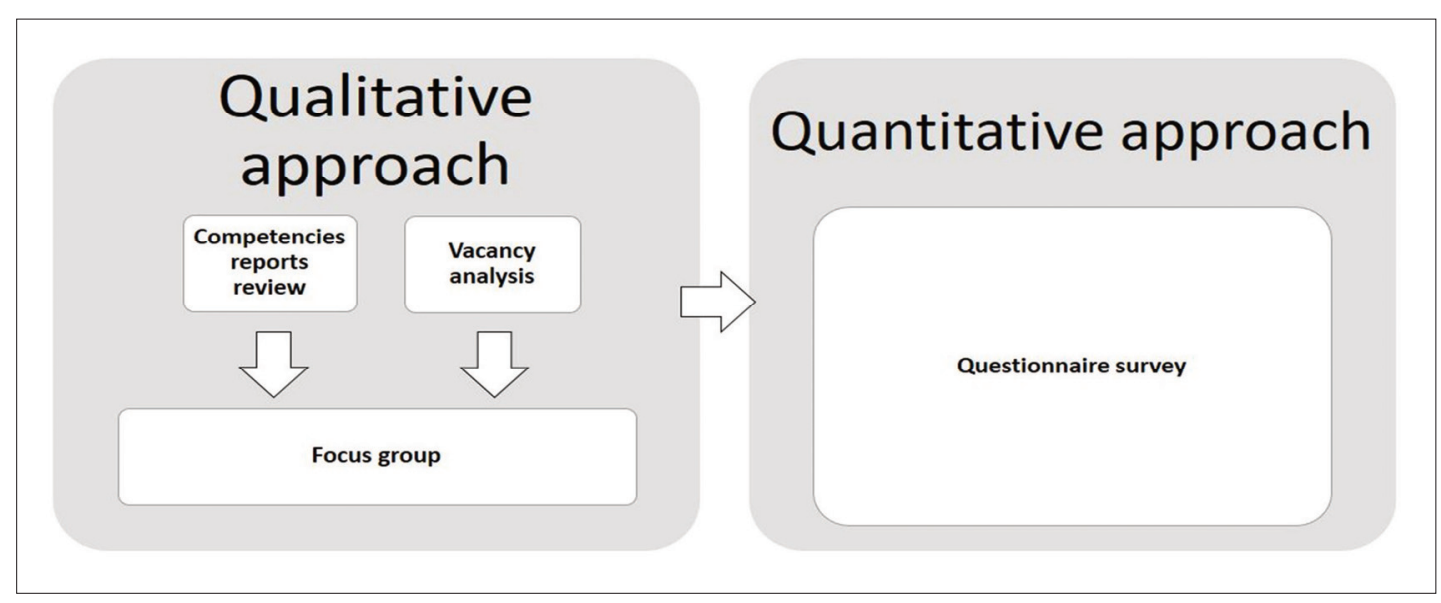

Figure 1: Methodology of the research

The aim of the first phase (qualitative part of the research) was to identify a list of competencies needed for employment in junior positions. It lasted during January and February 2019 and included content analysis of necessary competencies for entering the work environment (competences report review and vacancy analysis) and a focus group. Based on the results from the first phase, the research team created a questionnaire for the quantitative research.

\subsection{Qualitative approach}

\section{$1^{\text {st }}$ step: Competencies` reports review}

Identification of relevant competences report was conducted using keywords such as employment competences, graduates' competencies, general competencies, competencies for the future. Only publications including the keywords in the publication title or abstract were selected.

Inclusion criteria for reports selection was based on the following: presented research was done in several countries and several areas of business, and the research results show demand or the relevance of certain competencies for employment. The most prominent reports met the defined criteria and are discussed in more detail (Linkedln, Deloitte, WEF).

Coding of articles: To get a systematic overview and analyze the reports, the researchers singled out all the competencies that are mentioned as important for employment and made a unique list of 52 competencies. After that, all selected competencies were classified into categories according to similarity (for example: technical competencies, conceptual, interpersonal) and reports were compared to see whether certain competencies appear in several reports. 


\section{$2^{\text {nd }}$ step: Vacancy analysis}

Identification of relevant vacancies was done by listing competencies necessary for entering the work environment in junior positions found in job advertisements open in the period of January and February 2019 on the sites Linkedln and Infostud (large databases of job advertisements). We chose Linkedln as the most famous professional social network, known as the database of online CVs and ads, and Infostud because it is the first and most famous portal for advertising and job search in Serbia. The research team selected 100 job advertisements.

Inclusion criterion for the selection of open vacancy was that the position is in the field of management (with the aim of choosing as many different positions: marketing, sales, HR, finance, operations...) or IT; that it is an entry position, no previous work experience is required from the candidate; that the candidate must have a university diploma in the field of management or IT (FOS or other faculty), and it was based on 30 ads (available at that moment) that were further analysed in detail.

Job vacancies were coded and analysed according to the following items: position, necessary general competencies for employment, required knowledge, specific tasks. The inclusion criterion was met and all 30 ads were analysed. There were specific occupations from different areas of management which are studied more deeply within the subject at the FOS (example: Marketing Assistant, Recruitment and Selection Specialist, Production Operations Manager, Quality Assurance Manager) and Information Systems and Technologies (example: JavaScript Developer, Junior Test Developer, Junior PHP Developer)

\section{$3^{\text {rd }}$ step: Focus group}

The focus group was conducted according to Krueger and Casey's recommendations (2001) in February 2019 with seven experts in the field of Human resources (HR) with the experience in recruitment and selection process. The discussion was moderated by two HR experts from academia, i.e., co-authors of the article. The focus group was semi-structured and lasted for $1 \mathrm{~h} 50 \mathrm{~min}$. The conversation was recorded with the consent of all parties involved and then transcribed, resulting in a text of 12,079 words. We combined an inductive with a deductive coding approach, which means we took into consideration the participants' experience and perspective as well as the results of previous phases of this research. The backbone of the discussion was related to the recognition of the set of competencies of candidates for the first job. The set of necessary competencies for the first job was mapped by discussing the competencies gap of today's employees in junior positions.

\subsection{Quantitative approach}

The second phase of the research lasted from mid-March to mid-May 2019. The online scale based questionnaire (Cronbach's $\alpha(29)=.94$,) was sent to about 400 different sized companies operating in Serbia, that employ IT and Management graduates. Respondents from all tenure types (6 months to 30 years) are taken into consideration. The questionnaire was filled out by 118 representatives from companies from different business domains: informatics (45\%), trade (23\%), financial sector (13\%) and others (pharmacy, construction, energy, telecommunications - 19\%). The respondents were HR experts (41\%), directors and managers (22\%), recruiters (10\%), IT experts and other domain experts $(27 \%)$ involved in the employee selection process.

\section{Results}

The results obtained from each step of the research will be presented below the map of the required competencies for IT and management graduates to enter the labour market.

\subsection{Competency areas based on qualitative research}

From Linkedln, Deloitte and World Economic Forum the future of jobs reports, we extracted Creativity and Innovation as the competencies from the Entrepreneurial category exclusively, while Inititative is categorised in both Entrepreneurial and Soft skill categories. Critical thinking, Cooperation, and Adaptability are identified as strictly soft skills, while Time management is one of the competencies related with Workforce readiness. Analytical thinking and Programming fall into a category of Technical skills. 
The total number of competencies highlighted by the analysis of the reports content is 52 . Table 1 highlights the competencies that appear in two or all three reports, which is a total of 9 competencies that are recorded for more detailed analysis with experts during the focus group. It can be noticed that only Creativity appears in all reports as a necessary competency for employment.

Further, by listing the competencies that appear in current job advertisements, the research team defined additional 60 competencies, so the total number of competencies that represented the entry into the focus group was 69.

\section{Focus group results}

The most mentioned competency among the experts was taking responsibilities. According to the respondents, newcomers have developed no sense of what responsibility means and that is noticeable in their behaviour: "A sense of responsibility, which of course comes with age, is something that young people can hardly understand. Somehow they are thwarted by something that is ordinary work discipline."

The participants addressed conscientiousness as an important issue: "Today's people are all somehow less aware that there are some people around them who have some needs." Education plays a significant role in developing young people's awareness of themselves and the environment: "During their studies they can realize what role they like, which way they are most effective."

Analytical thinking was also recognized as a crucial competency especially considering the role of data and information in business. "Some awareness and orientation that if we do something, we make a decision, we start a project, it should be based on data, research, and not on an assumption or "we all know it's true" attitude." "It occurs to me in general, very broadly in all areas, that it should be talked more and more about data analytics, about decision-making, or any steps that are based on data, statistics, research. I think that is something that a lot of companies lack."

It was emphasized that the human qualities of a new employee were very important, and closely related to that of their attitude towards work. Ethics is imposed as a basis for building healthy interpersonal relationships and sustainable business. "To be a good man. That is primary! We are to return back to that."

During the analysis, we coded competencies identified from reports and vacancy analysis and added new codes based on transcript analysis. When a competency was mentioned for the first time in the transcript (and had not been recognized before) it became a new code meaning a new competency on the list. Eventually, the list of competencies was discussed among the authors of the paper until a mutual decision on 29 competencies classified into 4 categories: readiness for work, interpersonal, entrepreneurial and personal competencies, was reached (Table 1).

Table 1: List of competences from the qualitative research

\begin{tabular}{|l|l|l|l|}
\hline Readiness for work & $\begin{array}{l}\text { Interpersonal } \\
\text { competencies }\end{array}$ & $\begin{array}{l}\text { Entrepreneurial } \\
\text { competencies }\end{array}$ & $\begin{array}{l}\text { Personal } \\
\text { competencies }\end{array}$ \\
\hline Capability of continuous learning & Collaboration (teamwork) & $\begin{array}{l}\text { Work under } \\
\text { pressure }\end{array}$ & Self-confidence \\
\hline $\begin{array}{l}\text { Resourcefulness in a business } \\
\text { environment }\end{array}$ & $\begin{array}{l}\text { Competitiveness } \\
\text { (competitive spirit) }\end{array}$ & Innovation & Self-motivation \\
\hline Fitting into business values & Taking responsibility & Proactivity & Persistence \\
\hline Ability to adapt to change & Self-presentation & Creativity & Goal orientation \\
\hline Conscientiousness & $\begin{array}{l}\text { Leadership and social } \\
\text { influences }\end{array}$ & Curiosity & Ethics \\
\hline Problem solving & Communication skills & Independence & Social intelligence \\
\hline $\begin{array}{l}\text { Organizing and time } \\
\text { management }\end{array}$ & Presentation skills & Initiative & $\begin{array}{l}\text { Systematic and } \\
\text { analytical }\end{array}$ \\
\hline
\end{tabular}

\subsection{Competencies based on quantitative research}

Generally, looking into the whole sample, descriptive statistics show that the employees' most valued competencies are capability of continuous learning $(M=4.76, S D=0.62)$, conscientiousness $(M=4.69$, $S D=0.634$ ), collaboration (teamwork) $(M=4.47, S D=0.79)$, communication skills (active listening, assertiveness and accepting feedback) $(M=4.46, S D=0.78)$ and persistence $(M=4.42, S D=0.81)$ (Milinkovic, Andjelkovic Labrovic \& Petrovic, 2020). 
There are no differences between sectors (public and private), due to the discrepancies in the volume of the subsamples (more private sector companies), as well as between the size of the companies. We have, however, found differences between requirements for junior positions in different industries, so we have divided our sample into two categories: IT industry (junior IT positions) and other industries (junior managerial positions). $T$ test results show that differences detected in competitiveness $(t(116)=3,32, p<.001)$ and presentation skills $(\mathrm{t}(116)=2.92, p<.001)$ are seen as more crucial for junior managerial positions in other areas of business rather than the IT sector. Interestingly, those competencies are categorized in leadership and interpersonal competency areas. It was also found, but with a lower level of significance, that there are differences in conscientiousness (responsibility and reliability) $(\mathrm{t}(116)=2.4, p<.005)$ as one of the indicators of readiness for work and problem solving. According to differences based on empirically extracted competency areas (components), the only relevant difference is found for the Leadership component $(\mathrm{t}(116)=2.88, p<.005)$.

As the differences are only seen in three different competencies, and the means representing the importance of each and every competency are higher for other business areas in comparison with the IT sector, it is believed that maybe some specific knowledge is more important for IT than general competencies connected with readiness for work.

Further, there is an idea to reframe the categorisation of the competencies not according to the specific aspects of future work but rather meaning them to be more suitable for educational purposes in order to conceive and design teaching methods for specific skills development. We use Principal component analysis (Varimax rotation with Kaiser normalization) to extract four components that explain almost $57 \%$ of total variance (Table 2).

Table 2: Extracted components, item saturation and percentage of explained variance

\begin{tabular}{|c|c|c|c|c|c|}
\hline & \multicolumn{4}{|c|}{ Component } \\
\hline & & leadership & $\begin{array}{c}\text { problem } \\
\text { solving }\end{array}$ & creativity & $\begin{array}{c}\text { sociabilit } \\
y\end{array}$ \\
\hline \multirow{7}{*}{ 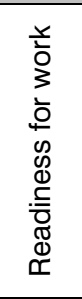 } & Capability of continuous learning & -.05 & .42 & .41 & .47 \\
\hline & $\begin{array}{l}\text { Resourcefulness in a business } \\
\text { environment }\end{array}$ & .41 & .15 & .12 & .59 \\
\hline & Fitting into business values & .19 & .25 & .18 & .64 \\
\hline & Ability to adapt to change & .18 & .12 & .29 & .65 \\
\hline & Conscientiousness & .05 & .63 & .31 & .23 \\
\hline & Problem solving & .16 & .68 & .16 & .06 \\
\hline & Organizing and time management & .56 & .36 & .05 & .35 \\
\hline \multirow{7}{*}{ 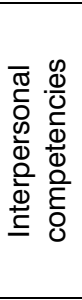 } & Collaboration (teamwork) & -.03 & .56 & .35 & .20 \\
\hline & $\begin{array}{l}\text { Competitiveness } \\
\text { (competitive spirit) }\end{array}$ & .6 & .03 & .15 & .14 \\
\hline & Taking responsibility & .48 & .53 & .27 & .1 \\
\hline & Self-presentation & .64 & .23 & -.03 & .19 \\
\hline & Leadership and social influences & .66 & -.05 & .38 & .31 \\
\hline & Communication skills & .369 & .29 & .44 & .25 \\
\hline & Presentation skills & .709 & .06 & .29 & .11 \\
\hline \multirow{8}{*}{ 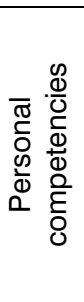 } & Self-confidence & .641 & .35 & .24 & -.05 \\
\hline & Self-motivation & .328 & .39 & .50 & .06 \\
\hline & Persistence & .278 & .67 & .28 & .16 \\
\hline & Goal orientation & .333 & .61 & .19 & .34 \\
\hline & Ethics & .102 & .45 & .15 & .57 \\
\hline & Social intelligence & .229 & .17 & .23 & .66 \\
\hline & Systematic and analytical & .216 & .69 & -.06 & .27 \\
\hline & Flexibility & .195 & .55 & .1 & .46 \\
\hline \multirow{8}{*}{ 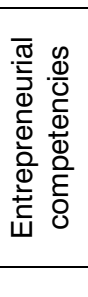 } & Work under pressure & .490 & .19 & .04 & .47 \\
\hline & Innovation & .270 & .05 & .75 & .16 \\
\hline & Proactivity & .217 & .29 & .69 & .24 \\
\hline & Creativity & .223 & .15 & .74 & .07 \\
\hline & Curiosity & -.004 & .21 & .68 & .24 \\
\hline & Independence & .597 & .23 & .27 & .23 \\
\hline & Initiative & .401 & .22 & .63 & .25 \\
\hline & $\%$ of Variance & 15.3 & 15.19 & 14.21 & 12.23 \\
\hline
\end{tabular}




\begin{abstract}
Based on the contents of the items included in components, four areas of competencies are created. The leadership component is saturated with the competencies describing one as a self-confident, self-sufficient, competitive, influential and efficient leader who knows how to deliver, present information - self-confident competitive leadership competencies. The problem-solving component describes an analytical and focused problem solver who is reliable, dependable and flexible teamwork player - analytical problem-solving competencies. The creativity component emphasizes a collection of traits integrating innovation and creativity, proactivity and initiative with curiosity and intrinsic motivation - intrinsically motivated creation competencies. The sociability component consists of self-controlled and ethical value compliance that helps to adapt to organizational reality and changes based on empathy, social intelligence and learning capacities - competencies needed for social adaptation.
\end{abstract}

Competencies that are expected from employees are to be a socially skilled leader capable of solving problems and intrinsically motivated to create and to be productive.

\title{
Discussion and Conclusion
}

Within this paper, two competency areas relevant for junior positions in an organisation were presented. First, based on combination of theoretical considerations and focus group results, the competencies were categorized into the following: readiness for work, interpersonal, entrepreneurship and personal. The second categorization is derived from the quantitative componential analysis of the respondents' answers. The scale items formed four sets of competencies: leadership, problem solving, creativity and sociability. Our empirically defined dimensions are similar to some other authors ' findings. For example, some researchers recognised creativity and problem solving (Jerman, et al., 2020; Grzybowska \& Lupicka, 2017; Suarta et al., 2017) and Macnamara (2018) recognised leadership and sociability.

Easterly et al. (2017) recognised personal, leadership and communication. Their personal characteristics integrate problem solving and creativity, while other dimensions also cover some aspects included in different categories. Leadership and sociability might loosely be seen as affective, and problem solving and creativity (referring to mental processes) as a cognitive one in Finch`s framework (2016).

Each component consists of a variety of competencies from different competencies' domains enabling a person to be capable of dealing with tasks that each domain requires. It is presented that the first component which describes prevalently leadership behaviours is more important for junior managerial positions in different areas of business than it is relevant for IT junior positions, as it is the case with interpersonal competencies. Additionally, detailed results show that ability and willingness to learn is ranked as the most needed competency for employment, as did the results of Pang et al. (2018).

We found that this re-categorisation of the competency domains is more suitable for adjusting educational programmes in order to fit the demands of the future employers. Bearing in mind the importance of responding to the employers demands when preparing students to start their future careers, we recommend that curricula should be adjusted in a way that enables the development of these competencies.

Perceptions of competencies and their categories vary among studies and industries, as well as methodological approaches. It is hard to form one universal yet sufficiently specific categorization that can be implemented for different population and different purposes. This one is valid for the population we considered and has no intention to be imposed as the omnipotent and general model of organizing competencies. Yet, we believe it could help scholars to choose a suitable path toward conceptualizing competencies and universities to adjust curricula in order to provide for the development of competencies that this labour market requires. In order to implement competency-based education, a more practical approach such as 'real-world' projects (Khoo, Zegwaard, \& Adam, 2018) should be implemented, as well as career counselling (Lo, 2019) and career management competencies development (Jackson \& Wilton, 2016). It is important, especially for Serbian universities, to innovate their courses and teaching methods so competencies that are identified as important should be developed through many different courses in the study programme. This means that the approach should be changed, in that within each subject, regardless of which field of study it belongs to, in addition to domain knowledge, a focus should be placed on adding activities that develop these competencies.

The main weakness of this study is in its scope, as it includes only a restricted set of occupational profiles. Nevertheless, it is expected to shape the educational programmes to be more viable. Also, while these dimensions are rather abstract, the potential implementation is limited. Further research and activities should go toward a more precise specification in order to make them applicable and easier to integrate into curricula. It would make it possible to adapt and create concrete examples of training and educational programmes within existing or emerging courses. 


\section{Acknowledgments}

Parts of this paper have been presented at the XVII International Symposium Symorg 2020 -"Business and Artificial Intelligence". The paper, as best presented in its session, has been recommended for further extension and review in the Management: Journal of Sustainable Business and Management Solutions in Emerging Economies.

\section{REFERENCES}

[1] Agnihotri, S., Sareen, P., \& Sivakumar, P. (2018). Role of competencies in employability readiness of graduates: A review. Advance and Innovative Research, 5(4), 557-561.

[2] Bedwell, W. L., Fiore, S. M., \& Salas, E. (2014). Developing the future workforce: An approach for integrating interpersonal skills into the MBA classroom. Academy of Management Learning \& Education, 13(2), 171186. DOI: $10.5465 /$ amle.2011.0138

[3] Bharwani, S., \& Talib, P. (2017). Competencies of hotel general managers: A conceptual framework. International Journal of Contemporary Hospitality Management.29(1), 393-418. DOI: 10.1108/IJCHM-092015-0448

[4] Bughin, J., Seong, J., Manyika, J., Chui, M., \& Joshi, R. (2018). Notes from the Al frontier: Modeling the impact of $\mathrm{Al}$ on the world economy. McKinsey Global Institute.

[5] Chen, L. (2020). Identifying Job Categories and Required Competencies for Instructional Technologist: A Text Mining and Content Analysis (Doctoral dissertation, Virginia Tech).

[6] Crespin, K. P., Holzman, S., Muldoon, A., \& Sen, S. (2017). Virginia's workplace readiness skills: Framework for the future. University of Virginia Weldon Cooper Center for Public Service, Demographics Research Group

[7] Deloitte and The Global Business Coalition for Education (2018). Preparing tomorrow's workforce for the Fourth Industrial Revolution. For business: A framework for action.

[8] Easterly III, R. G., Warner, A. J., Myers, B. E., Lamm, A. J., \& Telg, R. W. (2017). Skills Students Need in the Real World: Competencies Desired by Agricultural and Natural Resources Industry Leaders. Journal of agricultural education, 58(4), 225-239.

[9] El Asame, M., \& Wakrim, M. (2018). Towards a competency model: A review of the literature and the competency standards. Education and Information Technologies, 23(1), 225-236. DOI: 10.1007/s10639-0179596-z

[10] Esser, A., Kahrens, M., Mouzughi, Y., \& Eomois, E. (2018). A female leadership competency framework from the perspective of male leaders. Gender in Management: An International Journal, 33(2), 138-166. DOI: 10.1108/GM-06-2017-0077

[11] Finch, D. J., Peacock, M., Levallet, N., \& Foster, W. (2016). A dynamic capabilities view of employability. Education+ Trainin, 58(1), 61-81. DOI: 10.1108/ET-02-2015-0013

[12] Gawrycka, M., Kujawska, J., \& Tomczak, M. (2020). Competencies of graduates as future labour market participants-preliminary study. Economic research- Ekonomska istraživanja, 33(1), 0-0. DOI: $10.1080 / 1331677 X .2019 .1631200$

[13] Gervais, J. (2016). The operational definition of competency-based education. The Journal of Competency-Based Education, 1(2), 98-106. DOI: 10.1002/cbe2.1011

[14] Grzybowska, K., \& Łupicka, A. (2017). Key competencies for Industry 4.0. Economics \& Management Innovations, 1(1), 250-253

[15] Hodge, K. A., \& Lear, J. L. (2011). Employment Skills for 21st Century Workplace: The Gap Between Faculty and Student Perceptions. Journal of Career and Technical Education, 26(2), 28-41.

[16] Hurrell, S. A. (2016). Rethinking the soft skills deficit blame game: Employers, skills withdrawal and the reporting of soft skills gaps. Human Relations, 69(3), 605-628.DOI: 10.1177/0018726715591636

[17] Jackson, D., \& Wilton, N. (2016). Developing career management competencies among undergraduates and the role of work-integrated learning. Teaching in Higher Education, 21(3), 266-286. DOI:10.1080/13562517.2015.1136281

[18] Jerman, A., Pejić Bach, M., \& Aleksić, A. (2020). Transformation towards smart factory system: Examining new job profiles and competencies. Systems Research and Behavioral Science, 37(2), 388-402. DOI: $10.1002 /$ sres.2657

[19] Johnstone, S. M., \& Soares, L. (2014). Principles for developing competency-based education programs. Change: The Magazine of Higher Learning, 46(2), 12-19. DOI: 10.1080/00091383.2014.896705

[20] Khan, S. (2018). Demystifying the impact of university graduate's core competencies on work performance: A Saudi industrial perspective. International Journal of Engineering Business Management, 10, DOI: $10.1177 / 1847979018810043$

[21] Khoo, E., Zegwaard, K., \& Adam, A. (2018). Employer and lecturer perceptions of science and engineering graduate competencies: Implications for curricular and pedagogical practice. In 29th Australasian Association for Engineering Education Conference 2018 (AAEE 2018) (p. 377). Engineers Australia

[22] Kleckner, M. J., \& Marshall, C. R. (2014). Critical communication skills: Developing course competencies to meet workforce needs. The Journal of Research in Business Education, 56(2), 59-81. 
[23] Krueger, R. A., \& Casey, M. A. (2001). Designing and conducting focus group interviews. In Krueger, R. A., Casey, M. A., Donner, J., Kirsch, S., \& Maack, J. N. (Eds.), Social analysis: selected tools and techniques (pp. 4-24). Washington DC: World Bank. Retrivied from http://citeseerx.ist.psu.edu/viewdoc/download?doi=10.1.1.607.4701\&rep=rep1\&type =pdf

[24] Lo.,C.H., (2019). A Study of the Influence of Career Counseling Perception on the Employment Competencies of Design Students in Central Taiwan. Applied Sciences, 9(23), 5072. MDPI AG. DOI:10.3390/app9235072

[25] Maaleki, A. (2018). The ARZESH competency model: Appraisal \& development manager's competency model. LAP Lambert Academic Publishing.

[26] Macnamara, J. (2018). Competence, competencies and/or capabilities for public communication? A public sector study. Asia Pacific Public Relations Journal, 19, 16-40.

[27] Milinkovic, I., Andjelkovic Labrovic, J. \& Petrovic, N. (2020). Demand for competencies in 21st century workplace: companies expectations from graduates. Proceedings of the XVII International Symposium SymOrg 2020.

[28] Pang, E., Wong, M., Leung, C. H., \& Coombes, J. (2018). Competencies for fresh graduates' success at work: Perspectives of employers. Industry and Higher Education, 33(1), 55-65. DOI:10.1177/0950422218792333

[29] Pérez-López, M. C., González-López, M. J., \& Rodríguez-Ariza, L. (2016). Competencies for entrepreneurship as a career option in a challenging employment environment. Career Development International, 21 (3), 214-229. DOI:10.1108/cdi-07-2015-0102

[30] Pompa, C. (2015). Jobs for the Future. Overseas Development Institute. Retrieved from http://www.odi.org/sites/odi.org.uk/files/odi-assets/publications-opinion-files/9578.pdf

[31] Ritter, B. A., Small, E. E., Mortimer, J. W., \& Doll, J. L. (2017). Designing Management Curriculum for Workplace Readiness: Developing Students' Soft Skills. Journal of Management Education, 42(1), 80-103. DOI:10.1177/1052562917703679

[32] Sangka, B. K., Rahman, S., Yadlapalli, A., \& Jie, F. (2019). Managerial competencies of 3PL providers. The International Journal of Logistics Management, 30(4), 1054-1077. DOI:10.1108/IJLM-04-2019-0098

[33] Silva, V. V. M., \& Ribeiro, J. L. D. (2020). A discussion on using quantitative or qualitative data for assessment of individual competencies. Personnel Review. DOI: 10.1108/PR-08-2019-0444

[34] Silveyra, G., Herrero, Á., \& Pérez, A. (2020). Model of Teachable Entrepreneurship Competencies (M-TEC): Scale development. The International Journal of Management Education, in press. DOI: 10.1016/j.ijme.2020.100392

[35] Suarta, I. M., Suwintana, I. K., Sudhana, I. F. P., \& Hariyanti, N. K. D. (2017, September). Employability skills required by the 21st century workplace: A literature review of labor market demand. In International Conference on Technology and Vocational Teachers (ICTVT 2017). Atlantis Press.

[36] Varga, E., Szira, Z., Bárdos, K. I., \& Hajós, L. (2016). The most relevant labour market competencies for employers and their assessment by students. Practice and theory in systems of Education, 11(2), 95-104.

[37] Volery, T., Müller, S., Oser, F., Naepflin, C., \& Rey, N. D. (2013). The impact of entrepreneurship education on human capital at upper-secondary level. Journal of Small Business Management, 51(3), 429-446.

[38] Weaver, P., \& Kulesza, M. (2014). Critical skills for new accounting hires: What's missing from traditional college education. Academy of Business Research Journal, 4(1), 34-49.

[39] World Economic Forum. (2018, December). The future of jobs report 2018. Geneva: World Economic Forum.

Received: 2020-11-12

Revision requested: 2020-12-17

Revised: 2020-12-30 (1 revision)

Accepted: 2021-01-11

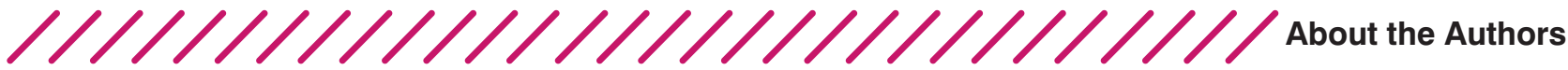

\section{Jelena Anđelković Labrović \\ University of Belgrade, Faculty of Organizational Sciences, Serbia jelena.andjelkovic.labrovic@fon.bg.ac.rs}

Jelena Andjelković Labrović is an Assistant Professor at the University of Belgrade, Faculty of Organizational Sciences, Department of Human Resources Management. She teaches the following subjects: Training and Development, E-learning, Human Resource Management and International Human Resource Management. She is the author or co-author of many research papers in the field of human resources, and her

particular interest is in e-learning of employees. She has participated in the implementation of several projects in companies in the field of human resource management as a consultant or researcher.

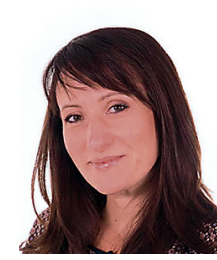




\section{Ivana Milinković}

University of Belgrade, Faculty of Organizational Sciences, Serbia ivana.milinkovic@fon.bg.ac.rs

Ivana Milinković is a Teaching Assistant at the Faculty of Organizational Sciences, University of Belgrade, Human Resource Management Department, where she teaches the following courses: Business Psychology, Teamwork, Interpersonal relations and Group Dynamics, Leadership and Motivation. She is also a Ph.D. student interested in the fields of motivation, assessment and development of employee competencies, and leadership.

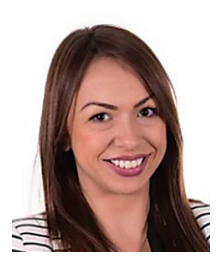

Nikola Petrović University of Belgrade, Faculty of Organizational Sciences, Serbia Nikola.petrovic@fon.bg.ac.rs

Nikola Petrović is a Teaching Assistant and PhD student at the University of Belgrade, Faculty of Organizational Sciences, Department of Human Resources Management. He teaches courses in Training and Development, E-learning and Human Resource

Management. His main fields of interest include learning analytics, learning engagement, HR automation, and ethical aspects of learning process automation.

Ivana Kovačević University of Belgrade, Faculty of Organizational Sciences, Serbia ivana.kovacevic

Ivana Kovačević is an Associate Professor at the University of Belgrade, Faculty of Organizational Sciences, Department of Human Resources Management. She obtained her PhD degree in Psychology at the Faculty of Philosophy at the University of Belgrade. She teaches courses in the field of Business Psychology, Human Relations, Teamwork and Group Dynamics, Leadership and Motivation. She is the author and co-author of papers and active in projects and research covering employee's motivation, conflicts, digital competencies and psychological aspects of Human-Computer Interaction. 